\title{
PROJETO NOVA VIDA: A ATUAÇÃO INTERDISCIPLINAR EM UMA COMUNIDADE TERAPÊUTICA
}

\author{
ROBERTO EPIFANio TOMAZ ${ }^{1}$ \\ ORCID: 0000-0003-4806-5113 \\ Karina Elisa Machado ${ }^{2}$ \\ ORCID: 0000-0003-0227-6468 \\ Josiane Aparecida Ferrari de Almeida Prado 3 \\ ORCID: 0000-0003-4806-5113
}

Doutor e Mestre em Ciência Jurídica pela Universidade do Vale do Itajaí, Doutor em Diritto Pubblico pela Università degli Studi di Perugia, Itália, tendo realizado doutorado sanduíche com bolsa CAPES mediante processo no ${ }^{\circ}$ 18033-12-1, na Universidade do Minho, em Braga, Portugal, professor de Direito Empresarial dos cursos de Graduação e Pós-Graduação (Lato Sensu) em Direito pela Universidade do Vale do Itajá, onde também Coordena os cursos de Pós-Graduação em Direito Empresarial e dos Negócios e em Direito Previdenciário e do Trabalho, atua também como advogado.. E-mail: (tomaz@univali.br).

2 Doutora em Farmácia pela Universidade Federal de Santa Catarina, professora dos Cursos de Estética e Cosmética e Estética e Cosmética Flexível, ministrando as disciplinas de Cosmetologia Básica, Cosmetologia Aplicada 1, Cosmetologia Aplicada 2, Fisiologia, Bases Biológicas e Trabalho de Iniciação Científica. E-mail: (karymachado@hotmail.com, karinaelisa@univali.br).

3 Possui Graduação em Curso de Formação de Psicólogo pela Universidade do Sagrado Coração, Especialização em Psicologia para Magistério Superior pela Universidade do Vale do Itajaí, Mestrado em Psicologia pela Universidade Federal de Santa Catarina e Especialização em Saúde da Família pela PUC-PR. É professora titular do curso de Psicologia da Universidade do Vale do Itajaí. Possui experiência na área de Psicologia Clínica e Psicologia da Saúde, desenvolvendo atividades em Psico-Oncologia. Atua também como Supervisora de Estágio no modelo clínico da Gestalt-Terapia. E-mail: (jprado@univali.br). 
Resumo: O presente artigo apresenta um breve relato dos resultados dos trabalhos do Projeto de Extensão Nova Vida no Ano de 2018. O objetivo proposto é de colaborar com o aumento do índice de recuperação e reinserção dos dependentes químicos em tratamento nos ambientes sociais familiares e profissionais. Para tanto, o relato foi formado nas três áreas de atuação do projeto: jurídica, farmacêutica e psicológica. Quanto à Metodologia, foi utilizada a base lógica Indutiva, além das Técnicas do Referente, da Categoria, do Conceito Operacional e da Pesquisa Bibliográfica e Documental. Os resultados apontam uma efetiva contribuição na reinserção social, familiar e laboral dos dependentes químicos acolhidos na Comunidade Terapêutica Nova Vida, indicando a necessidade da ampliação ao atendimento às famílias e aos familiares dos acolhidos, bem como do acompanhamento terapêutico daqueles que finalizam o período de tratamento.

Palavras-chave: Extensão. Recuperação. Reinserção. Dependentes químicos.

\title{
PNEW LIFE PROJECT: THE INTERDISCIPLINARY ACTION IN A THERAPEUTIC COMMUNITY
}

\begin{abstract}
The present article presents a brief report of the results of the work of the "Projeto de Extensão Nova Vida" in the year of 2018. The proposed objective is to collaborate with the increase of the index of recovery and reinsertion of the chemical dependents in treatment in the familiar and professional social environments. For this, the report was formed in three areas of action of the project: legal, pharmaceutical and psychological. As for the Methodology, the Inductive Logic base was used, as well as Referent Techniques, Category, Operational Concept and Bibliographic and Documentary Research. The results point to the collaboration of the project in the social reinsertion of the chemical dependent, as well as indicate chemical dependence as a disease, indicating the need to expand the care to the families and families of the shelters, as well as the therapeutic accompaniment of those who finish the treatment period. Keywords: Extension. Recovery. Reinsertion. Chemical dependents.
\end{abstract}

\section{PROYECTO NUEVA VIDA: LA ACTUACIÓN INTERDISCIPLINAR EN UNA COMUNIDAD TERAPÉUTICA}

Resumen: El presente artículo presenta un breve relato de los resultados de los trabajos del "Projeto de Extensão Nova Vida" en el año 2018. El objetivo propuesto es de colaborar con el aumento del índice de recuperación y reinserción de los dependientes químicos en tratamiento en los ambientes sociales familiares y profesionales. Para ello el relato se formó en las tres áreas de actuación del proyecto: jurídica, farmacéutica y psicológica. En cuanto a la Metodología, se utilizó la base lógica Indutiva, además de las Técnicas del Referente, de la Categoría, del Concepto Operativo y de la Investigación Bibliográfica y Documental. Los resultados apuntan a la colaboración del proyecto en la reinserción social del dependiente químico, así como indican la dependencia química como enfermedad, indicando la necesidad de ampliar la atención a las familiares de los acogidos, asi como el acompañamiento terapêutico de quines terminan el período de tratamento. 
Palabras claves: Extensión. La recuperación. Reinserción. Dependientes químicos.

Submetido em: 27/08/2019.

Aceito em: 27/09/2019.

\section{INTRODUÇÃO}

O presente artigo apresenta o relato das ações e dos resultados obtidos na realização do "Projeto de Extensão Nova Vida" no Ano de 2018, e sugestões para a implementação na sua continuidade no ano de 2019.

O uso de substâncias psicoativas é considerado um problema de saúde pública. Tais substâncias são utilizadas para produzir alterações nas sensações, no grau de consciência ou no estado emocional. Tanto as drogas lícitas (álcool) como as ilícitas (maconha, cocaína e crack, por exemplo) são potencialmente perigosas. As alterações causadas pelo consumo dessas substâncias variam de acordo com o tipo de droga utilizada, quantidade, características da pessoa que as usa, efeito que a substância gera e circunstâncias nas quais é consumida.

O uso abusivo dessas substâncias aumenta a vulnerabilidade psicossocial dos usuários gera inúmeras consequências à saúde decorrentes dos comportamentos de risco associados ao consumo (DST/AIDS, por exemplo) e a ausência do produto pode causar síndrome de abstinência e sintomas psiquiátricos.

Para Organização Mundial de Saúde o uso abusivo de substâncias psicoativas propicia prejuízos psicológicos, biológicos e sociais. Como forma de lidar com essa realidade e auxiliar no tratamento e reabilitação o presente artigo busca apresentar a importância da atuação da equipe interdisciplinar composta pelos cursos de direito, farmácia e psicologia no acompanhamento aos dependentes químicos da Comunidade Terapêutica Nova Vida.

Quanto à Metodologia, o relato dos resultados é composto na base lógica Indutiva. Nas diversas fases da Pesquisa, foram utilizadas as Técnicas do Referente da Categoria, do Conceito Operacional e da Pesquisa Bibliográfica, esta última, pela via eletrônica.

\section{COMUNIDADES TERAPÊUTICAS}

As Comunidades Terapêuticas (CTs) são instituições privadas e sem fins lucrativos que prestam serviços de acolhimento e tratamento às pessoas que fazem uso 
abusivo de substâncias psicoativas. O acolhimento é realizado de forma voluntária e em regime residencial. As CTs credenciadas pela Federação Brasileira de Comunidades Terapêuticas (FEBRACT) oferecem um programa terapêutico como proposta a abordagem de autoajuda, além das práticas médicas e psicológicas.

A Portaria $\mathrm{n}^{\circ} 131$ de 26 de janeiro de 2010, versa que as Comunidades Terapêuticas (CTs) promovem serviços de atenção à saúde em regime residencial e transitório para adultos com necessidades clínicas estáveis decorrentes do uso de álcool, crack e outras drogas. Em seu artigo $6^{\circ}$, a Portaria embasa os projetos técnicos às seguintes diretrizes: respeitar, garantir e promover os diretos do residente como cidadão; ser centrado nas necessidades do residente, em consonância com a construção da autonomia e a reinserção social; garantir ao residente o acesso a meios de comunicação; garantir o contato frequente do residente com a família desde o início da inserção na entidade; respeitar a orientação religiosa do residente; garantir o sigilo das informações prestadas pelos profissionais de saúde, familiares e residentes; inserção da entidade na Rede de Atenção Psicossocial, em estreita articulação com os CAPS, a Atenção Básica e outros serviços pertinentes; permanência do usuário residente na entidade por no máximo 6 (seis) meses, com a possibilidade de prorrogação por mais 3 (três) meses.

Na Comunidade Nova Vida os internos/acolhidos podem permanecer no máximo 9 (nove) meses, são recebidos por indicação da Secretaria da Saúde dos municípios da região do Vale do Itajaí e/ou por indicação de familiares que procuram a entidade.

Os acolhidos recebem atendimento e acompanhamento através da equipe de colaboradores da Comunidade Terapêutica durante todo o período de permanência, inclusive com acompanhamento médico, psicológico e farmacêutico.

Dentre as diversas atividades exercidas pelos acolhidos na Comunidade Terapêutica Nova Vida, estão atividades laborais, de estudo (na Comunidade funciona uma unidade do EJA - Educação de Jovens e Adultos), espirituais, de educação física, bem como participar das atividades realizadas semanalmente no Projeto de Extensão Nova Vida que colaboram com o período terapêutico de forma interdisciplinar, trazendo atividades que norteiam os campos da psicologia, direito e farmácia.

\section{INTERDISCIPLINARIDADE}

Os projetos de extensão favorecem importantes intercâmbios com disciplinas, metodologias, cursos e instituições para acadêmicos e professores. Contribuem para a ampliação de novas oportunidades educacionais colaborando com 
a mudança na formação tecnicista para a formação pautada na integralidade, visando ações humanizadas e o desenvolvimento de políticas públicas regionais, "pela imersão, professores, alunos e comunidade se unem, se fortalecem, criam vínculos, alinhando saberes, promovendo mudanças".

O "Projeto de Extensão Nova Vida" promove a atuação interdisciplinar, pois é a realização de um trabalho tendo como foco as necessidades da comunidade. Os cursos de Direito, Farmácia e Psicologia criaram vínculos entre si para também vincularem com a população, pois atua com ela e não para ela.

Nesse projeto, a atuação interdisciplinar tem como base o suporte científico e social. Busca a mudança e no fortalecimento da cidadania às pessoas acolhidas na Comunidade Terapêutica, zelando pelo princípio ético e respeito à vida. A metodologia utilizada para orientar, informar favorecer o encontro com os internos/ acolhidos foi a roda de Conversa, que segundo Giorgi:

Procura criar um espaço de interação entre os participantes, num ambiente favorável para que expressem suas ideias, impressões, conceitos, opiniões e concepções sobre o tema proposto. Desta forma, permite trabalhar reflexivamente as manifestações apresentadas pelo grupo, nos quais todos são ouvidos e as discussões são permeadas por um coordenador. (GIORGI, 2017, p.128)

Através da roda de conversa, de forma interdisciplinar, informações são repassadas sobre direito e cidadania, substâncias psicoativas, educação em saúde e são realizadas dinâmicas de grupo tendo o interno/acolhido como foco. As dinâmicas de grupo buscam a mobilização dos internos/acolhidos para a descoberta de seus significados e propósitos de vida.

\section{ESPIRITUALIDADE}

O Projeto, através da roda de conversa, procura trabalhar com as pessoas que ali estão por vontade própria (pois as internações são sempre voluntárias) favorecendo o acolhimento através de uma escuta respeitosa e atenta, valorizando a individualidade - compreendendo as necessidades de cada pessoa como única.

Este é um enfoque pautado na visão integral do ser humano, compreendendo que as dimensões da existência humana são contempladas em seus aspectos biopsicossocio-culturais e espirituais.

Para Luczinski e Ancona-Lopes a dimensão biológica se manifesta pela corporeidade; a dimensão psicológica se refere à forma como a pessoa vivencia a sua existência no mundo, emoções e reações (pessoas têm necessidades diferentes e também 
reagem de formas diferentes às cobranças do meio); na dimensão social e cultural a pessoa se relaciona com o meio (com os outros seres) herdando uma cultura, recebendo informações e também transformando o meio que vive; a dimensão espiritual está presente em todas as manifestações humanas, são as reações das pessoas frente às vivências que a acomete e sua capacidade de transformar-se, transcender e dar significado e sentido à própria existência, exercendo sua vontade, sua liberdade e sua responsabilidade, conhecendo e respeitando seus limites.

Para Dall-Farra e Geremia:

A espiritualidade se refere a um amplo domínio da subjetividade humana, refletindo nos valores e ideais mais preciosos das pessoas, assim como o senso de quem são, as suas crenças, o significado e o propósito de suas vidas junto à conexão que elas estabelecem com os outros e com o mundo em que vivem. (DALL-FARRA; GEREMIA, 2010, p. 587-597)

Cabe neste ponto definir acepção adotada pelos autores acima citados para diferenciar religião de espiritualidade:

Religião passou a ser entendida como prática institucionalizada de um sistema de crenças, rituais e símbolos, compartilhada por uma comunidade. Espiritualidade, por sua vez, pode ser entendida como uma busca pessoal por significado e sentido maior no existir e sua relação com o sagrado e o transcendente, podendo estar vinculada ou não a uma religião formalizada ou designação religiosa. (DALL-FARRA; GEREMIA, 2010, p. 587-597)

Na perspectiva da Psicologia Existencial Fenomenológica o homem é ontologicamente diferente dos demais seres, está em permanente construção, cada qual com seus valores e necessidades, influenciando e sendo influenciado pelo meio. Quando as influências do meio são maiores do que o conceito que tem sobre si mesmo, a pessoa perde sua capacidade de discernimento, não sabendo quais são suas necessidades, perdendo sua habilidade de fazer escolhas saudáveis.

$\mathrm{Na}$ roda de conversa com a proposição das ações interdisciplinares há uma relação dialógica entre professores, acadêmicos e internos/acolhidos, tendo como premissa o respeito à singularidade e a construção conjunta da busca de sentidos.

\section{DEPENDÊNCIA QUÍMICA AO OLHAR DO DIREITO E DA MEDICINA}

De acordo com a Classificação Internacional de Doenças (CID-10), a dependência química caracteriza-se pela presença de um agrupamento de sintomas 
cognitivos, comportamentais e fisiológicos, indicando que o indivíduo continua utilizando uma substância, apesar de problemas significativos relacionados a ela.

Como acrescentam Kaplan, Sadock e Grebb, o indivíduo dependente prioriza o uso da droga em detrimento de outras atividades e obrigações.

A temática dependência química se faz presente no cotidiano de nossa sociedade, o assunto é discutido através da mídia e no seio da grande maioria das famílias, a preocupação com a forma maléfica que a dependência química provoca nos dependentes e na fragilidade das famílias atingidas pelos constantes conflitos causados pelo uso constante impulsionado pelo forte desejo pela substância psicoativa.

O uso contínuo da droga faz com que o indivíduo manifeste um comportamento mais violento que o habitual, uma vez que a fissura pelo consumo, a qual é determinada pela condição de abstinência da droga, torna-se o gatilho para a prática de condutas criminosas.

Atualmente, a Organização Mundial de Saúde (OMS) considera o uso abusivo de drogas como uma doença crônica e recorrente. Para esta instituição, o uso de drogas constitui um problema de saúde pública, que vêm ultrapassando todas as fronteiras sociais, emocionais, políticas e nacionais, preocupando toda a sociedade.

Existe uma falsa Dicotomia ao se pretender tratar a Dependência Química ora como questão de Saúde ora como questão de Segurança Pública. Reitere-se a posição do STF que afirma serem as Drogas uma questão pertinente à essas duas áreas. Mas não há uma em detrimento da outra.

Fato é que é problema Individual e Coletivo, mas não há, ou deveria não haver, monopólio ou apropriação exclusiva de qualquer ramo da Ciência acerca do Saber referente à questão. Ela é mais do que multidisciplinar, é interdisciplinar, e abarca muito mais questões do que apenas aquelas afetadas ao Direito e a Medicina.

O Consumidor de Drogas e o Dependente Químico não são necessariamente a mesma pessoa. Uma coisa é degustar um bom vinho, outra é beber compulsivamente e destrutivamente, até entrar em Coma Alcoólico, por exemplo.

O Direito é uma das formas pelas quais as Sociedades, em qualquer tempo e espaço, se servem para serem estruturadas, e dar, de certa forma, a medida e o grau de sua estruturação

Ele permeia e passeia por todas as áreas do conhecimento humano. Até para fazer pesquisa pura em campos inovadores da ciência, de qualquer ciência e relativa a qualquer tecnologia, é necessária sua presença estruturante. Afinal, o Direito estrutura as relações entre as pessoas, entre si, e com as coisas.

A ordenação das vontades, dos desejos, das condutas, dos saberes, dos indivíduos e das relações sociais são efetuadas por meio da lei. A Lei é concreta e simbólica 
ao mesmo tempo, a qual não é dado a ninguém a possibilidade de alegar seu desconhecimento para se elidir de observá-la, cumpri-la ou transgredi-la, mas, nesse caso, embora o sujeito possa não conhecer os meandros do sistema legal, ele sabe, de alguma forma, que algo está lá, em uma escritura, e escolhe ou assume o risco de não lhe dar atenção.

Ambígua posição, já que concorrentemente à uma Tendência de Estruturação, existe um Sujeito que clama por Liberdade e Igualdade plena, ampla, geral e irrestrita.

Os seus Direitos podem e devem ser limitados na forma da Legislação existente. Na área Civil, a Interdição é o grande exemplo de Limitação de sua Capacidade para Exercer Direitos e Contrair Obrigações. A Internação Involuntária e a Compulsória são dois outros exemplos. Existe Lei específica para tratar das situações em que ele coloca sua Vida ou de Terceiros em risco

Segundo os padrões definidos na Lei 11.343/06 - denominada Lei Antidrogas que instituiu o Sistema Nacional de Políticas Públicas sobre Drogas (SISNAD) no qual se prescreve medidas para prevenção do uso indevido, atenção e reinserção social de usuários e dependentes de drogas e estabelece, também, as normas para repressão à produção não autorizada e ao tráfico ilícito de drogas e ainda define crimes e dá outras providências - pode-se entender que:

Art. 28. Quem adquirir, guardar, tiver em depósito, transportar ou trouxer consigo, para consumo pessoal, drogas sem autorização ou em desacordo com determinação legal ou regulamentar será submetido às seguintes penas:

I - Advertência sobre os efeitos das drogas;

II - Prestação de serviços à comunidade;

III - Medida educativa de comparecimento à programa ou curso educativo.

$\S 1$ òs mesmas medidas submete-se quem, para seu consumo pessoal, semeia, cultiva ou colhe plantas destinadas à preparação de pequena quantidade de substância ou produto capaz de causar dependência física ou psíquica.

$\$ 2$ o Para determinar se a droga destinava-se a consumo pessoal, o juiz atenderá à natureza e à quantidade da substância apreendida, ao local e às condições em que se desenvolveu a ação, às circunstâncias sociais e pessoais, bem como à conduta e aos antecedentes do agente.

$\S 3$ o As penas previstas nos incisos II e III do caput deste artigo serão aplicadas pelo prazo máximo de 5 (cinco) meses.

$\S 4$ o Em caso de reincidência, as penas previstas nos incisos II e III do caput deste artigo serão aplicadas pelo prazo máximo de 10 (dez) meses.

$\$ 50$ A prestação de serviços à comunidade será cumprida em programas comunitários, entidades educacionais ou assistenciais, hospitais, estabelecimentos 
congêneres, públicos ou privados sem fins lucrativos, que se ocupem, preferencialmente, da prevenção do consumo ou da recuperação de usuários e dependentes de drogas.

$\$ 60$ Para garantia do cumprimento das medidas educativas a que se refere o caput, nos incisos I, II e III, a que injustificadamente se recuse o agente, poderá o juiz submetê-lo, sucessivamente a:

I - Admoestação verbal;

II - Multa.

$\$ 7$ o O juiz determinará ao Poder Público que coloque à disposição do infrator, gratuitamente, estabelecimento de saúde, preferencialmente ambulatorial, para tratamento especializado.

No ano de 2018, seguindo modelo de anos anteriores em que o Projeto Nova Vida atuou, na área jurídica foram desenvolvidas atividades em grupo e atendimentos individuais, relacionadas com as necessidades dos internos acolhidos na Comunidade Terapêutica Nova Vida.

As atividades em grupo consistiram na reunião dos internos para esclarecimentos gerais sobre determinado assunto. Nesse sentido, observou-se que havia grande interesse sobre o benefício previdenciário do auxílio-doença, bem como em assuntos relacionados a direitos sociais, como a saúde, a habitação e o trabalho.

Foram também realizadas abordagem e entrevistas individuais com todos os internos para buscar informações sobre a situação familiar e profissional de cada acolhido. Nos atendimentos individuais, destacaram-se dois assuntos principais: o direito de família e o direito penal.

Numa perspectiva geral, as abordagens em grupo e individuais revelam que os dependentes químicos, em geral, acabam por serem rejeitados pela sociedade e pela família. Por esta razão, as orientações gerais buscaram a solução das controvérsias nos eventuais desentendimentos, visando o esclarecimento das responsabilidades legais do dependente químico e a sua total reinserção social, familiar e laboral.

\section{AÇÕES FARMACÊUTICAS}

Historicamente, a regulação do uso de substâncias psicoativas se estabeleceu em contextos sócio culturais específicos, que condicionaram o seu consumo mediante normas e convenções socialmente compartilhadas. Porém Alves cita que:

O isolamento de princípios ativos de substâncias psicoativas e sua industrialização no início do século XIX, somado a popularização crescente do consumo e ao próprio contexto histórico brasileiro, marcado por intensa urbanização, pauperização e aumento das 
desigualdades sociais, contribuíram para a concretização de uma emergente demanda social. (ALVES, 2009, p.19)

Destaca-se, que desde o início do século XX, o crescimento do uso destas substâncias ganhou evidência, configurando-se com um problema de saúde pública global, devido à dependência decorrente de seu uso, à gravidade de seus efeitos, que ultrapassa o limite do biológico, refletindo na sociedade, à severidade dos efeitos produzidos pelo seu uso crônico, e o aumento vertiginoso da prevalência do uso na população mundial.

O consumo e o impacto social do uso de drogas de abuso são temas de grande preocupação social. Resultados de diferentes pesquisas identificam o crescente aumento do consumo de drogas de abuso para fins recreativos, a redução da idade de iniciação e a facilidade de obtenção das drogas, devido a diferentes formas de produção e preços mais acessíveis.

Neste intento Scheffer, Pasa e Almeida completam que:

O início do consumo pode ocorrer por alguns motivos como: curiosidade, hedonismo, alívio para dor ou sofrimento, o que, provavelmente, ira persistir e aumentar após o início do consumo dessas substâncias. (SCHEFFER; ALMEIDA, 2010, p.533-541)

Neste contexto, em muitos dos casos, no tratamento da reabilitação química são utilizados os medicamentos psicotrópicos, aqueles fármacos que agem no Sistema Nervoso Central (SNC) produzindo alterações de comportamento, humor e cognição, influenciando diretamente o comportamento de cada pessoa. Para Carlini (2001), os medicamentos psicotrópicos utilizados para o tratamento algumas vezes são os mesmos utilizados na dependência química dos usuários.

Entretanto, Sehn (2003) destaca que a politerapia é muito útil no tratamento de patologias, incluindo dependência química, agindo principalmente no auxílio do controle de reações medicamentosas, na diminuição dos grandes efeitos adversos quando necessário e na ajuda da busca por diminuir os incômodos de um tratamento não terapêutico.

Conversas, grupos de apoio e palestras educativas também auxiliam no tratamento da dependência química, nesta perspectiva, na área farmacêutica, foram desenvolvidas palestras no Projeto de Reinserção Laboral, Familiar e Social de Dependentes de Substâncias Entorpecentes em Tratamento Terapêutico - ou apenas Projeto Nova Vida - os temas giraram em torno à área de farmácia com objetivo de informar, esclarecer e conscientizar aos "internos" da Comunidade Terapêutica Nova Vida acerca da realidade que os rodeia. 
Acredita-se que a exposição, discussão e orientação sobre os problemas relacionados com o uso das drogas, seu tratamento e como minimizar os efeitos das crises de abstinência se demonstrem de extrema relevância, auxiliando na convivência do acolhido no grupo e em família. Destaca-se que esses são dilemas diários vivenciados pelos acolhidos.

Os temas abordados envolvem, necessariamente, a prática e a necessidade do uso racional de medicamentos, em especial aos medicamentos calmantes e ansiolíticos - classe medicamentosa bastante utilizada pelos "internos" durante o tratamento - e a sua importância para reabilitação.

Igualmente se destaca a relevância da adesão ao tratamento para a promoção da saúde, pois comumente há casos em que o acolhido rejeita qualquer espécie de medicamento pelo fator de estar simplesmente "trocando o tipo de uso de droga", não percebendo a importância do uso de medicamentos para sua efetiva recuperação.

Há, ainda, a abordagem de temas relacionados à saúde dos acolhidos como as doenças crônicas - Diabetes Mellitus e Hipertensão -, as doenças sexualmente transmissíveis - HIV e Hepatite - e as doenças metabólicas - dislipidemias e obesidade -, patologias essas que acometem muitos dos acolhidos, gerando muitas dúvidas e discussão.

As palestras também envolvem o tema "Drogas", abordando seu histórico, suas consequências, diferenciando abstinência física da psicológica, explorando a tolerância e explicando como seu corpo reage às substâncias psicoativas e como é o processo de desintoxicação, conhecido como crise de abstinência.

Procurando estar sempre atualizado, esse ano, foi introduzido nas temáticas a série "Prisão Química", exibida pelo Fantástico, que relata a "luta" do ex-jogador de futebol Walter Casagrande, ídolo de muitos “internos", contra a cocaína. Destaca-se que esta série foi incluída a pedidos dos "internos", demonstrando interação entre o projeto e os acolhidos, a fim que as atividades sejam interativas e produtivas.

As palestras terminaram com o tema reinserção social, e conversas francas e diretas sobre "como voltar ao ambiente de convívio familiar, sem voltar ao consumo de drogas". Considerando que a recuperação total do paciente só pode ser alcançada após certo tempo, podendo se estender a anos de tratamento, o qual deve ser monitorado constantemente, mesmo após o fim da terapia proposta.

Assim, destaca-se a importância do farmacêutico junto a equipes e grupos multidisciplinares de trabalho, para uma efetiva promoção da saúde e desenvolvimento de reflexões críticas que possam gerar mudanças de comportamento e colaborar com a reinserção social, familiar e laboral de dependentes químicos, como se percebe no Projeto Nova Vida. 


\section{CONSIDERAÇÕES FINAIS}

O Projeto de Extensão Nova Vida é desenvolvido em caráter interdisciplinar por acadêmicos e professores da Universidade do Vale do Itajaí, em três principais focos de atuação, jurídico, farmacêutico e psicológico, em apoio ao tratamento terapêutico realizado com acolhidos na Comunidade Terapêutica Nova Vida, entidade sem fim lucrativo que já há mais de 27 anos vem acolhendo dependentes químicos e trabalha em prol de sua recuperação e recolocação social.

Como forma principal de abordagem dos acolhidos é utilizado a roda de conversas onde informações sobre direito e cidadania, substância psicoativas, educação e saúde são repassadas de forma dinâmica numa redescoberta de significados e propósitos de vida.

Na área do Direito vários assuntos foram abordados em esclarecimentos realizados em grupo ou individuais, sendo que algumas temáticas são recorrentes como família, pensão alimentícia, FGTS, questões criminais, de seguridade social e do trabalho.

A abordagem farmacêutica envolve desde a prática e a necessidade do uso racional de medicamentos que se torna extremamente relevante para adesão ao tratamento de saúde enquanto acolhidos na Comunidade Terapêutica Nova Vida, quanto aborda temas relacionados à saúde e doenças crônicas.

A abordagem psicológica revela a relevância do trabalho multidisciplinar, tendo em vista que a dependência possui aportes biológicos, psicológicos e sociais.

Os resultados revelam uma efetiva contribuição na reinserção social, familiar e laboral dos dependentes químicos acolhidos na Comunidade Terapêutica Nova Vida, bem como evidenciam a dependência química como doença que precisa ser abordada por diversas formas de tratamento no seio familiar e social, principalmente por dinâmicas e abordagens multidisciplinares como as adotadas no Projeto de Extensão Nova Vida.

Não obstante os excelentes resultados obtidos pelo projeto, percebe-se a necessidade de se ampliar o atendimento às famílias e aos familiares dos acolhidos, bem como do acompanhamento terapêutico daqueles que finalizam o período de tratamento. Intentos que o Projeto de Extensão Nova Vida procurará atender em sua continuidade. 


\section{REFERÊNCIAS}

ABREU, . M. M. et al. Perfil de consumo de substâncias psicoativas e sua relação com características sociodemográficas: contribuição para uma breve intervenção no cuidado primário de saúde. Revista Texto \& Contexto em Enfermagem, v. 25, n. 4 2016. Disponível em: http://www.scielo.br/pdf/tce/ v25n4/pt_0104-0707-tce-25-04-1450015.pdf. Acesso em: 01 nov 2018.

ALVES V. S. Modelos de atenção à saúde de usuários de álcool e outras drogas: discurso político, saberes e práticas. Cad Saúde Pública, v. 25, n. 11, 2009, p. 2309-19.

ANDRETTA, I.; OLIVEIRA, M. S. A entrevista motivacional em adolescentes usuários de droga que cometeram ato infracional. Psicologia: Reflexão e Crítica, 24(2),218-226. 2011.

CARLINI, E. A. et al. Drogas psicotrópicas: o que são e como agem. Revista IMESC n.3, 2001.

DAL-FARRA, R. A.; GEREMIA, C. Educação em saúde e espiritualidade: proposições metodológicas. Rev. bras. educ. med., v. 34, n. 4, 2010, p. 587-597. Disponível em: http://www.scielo.br/scielo.php?script=sci_ arttext\&pid=S0100-55022010000400015\&lng=en\&nrm=iso Acesso em: 13 nov. 2018.

GIORGI, M. D. M. et al. Extensão universitária na roda de conversa: articulação entre ensino e extensão. In: FARHAL, E. M. P.; DITTRICH, M. G. (orgs). Educação e Saúde: políticas públicas e vivências dialógicas. 1 ed. Itajaí: Editora da Universidade do Vale do Itajaí, 2017.

KAPLAN, H.; SADOCK, B.; GREBB, J. Compêndio de Psiquiatria: ciência do comportamento e Psiquiatria Clínica. 9. ed. Porto Alegre: Artes Médicas. 2007.

LORENZO, C. Vulnerabilidades em saúde pública: implicações para as políticas públicas. Rev Bioét 2006; 2(3): 299-31. 
LUCZINSKI, G. F.; ANCONA-LOPEZ, M. A psicologia fenomenológica e a filosofia de Buber: o encontro na clínica. Estud. psicol. Campinas, v. 27, n. 1, p. 75-82, mar. 2010. Disponível em: http://www.scielo.br/scielo.php?script=sci_ arttext\&pid=S0103-166X2010000100009\&lng=en\&nrm=iso. Acesso em: 14 Nov. 2018.

PASOLD, C. L. Metodologia da Pesquisa Jurídica: Teoria e Prática. 12 ed. rev. São Paulo: Conceito Editorial, 2011.

PLONER, K.; FONTOURA, L.; PRADO, J. A. F. A.; DELVAN, J. S. A extensão na universidade: documentos oficiais. In: SARDA JR, J.; DELVAN, J. S. (orgs). Psicologia na Univali: 30 anos na atuação da formação profissional. 1 ed. Itajaí: Editora da Universidade do Vale do Itajaí, 2017.

SCHEFFER. M.; PASA, G. G.; ALMEIDA, R. M. Dependência de Álcool, Cocaína e crack e transtorno psiquiátricos. Psicologia: teoria e pesquisa. v. 26, n. 3, p. 533-541, jul./set. 2010.

SEHN, R. Interações medicamentosas potenciais em prescrições de pacientes hospitalizados. Infarma. v. 15, n. 9-10, set./out. 2003.

SPRICIGO, J.S.; CARRARO, T.E.; CARTANA, M.H.F.; REIBNITZ, K.S. Atenção ao usuário de drogas - um espaço para o enfermeiro. Texto Contexto Enferm, v. 13, 2004, p. 296-302.

WORLD HEALTH ORGANIZATION. World Health Statistics 2016: Monitoring health for the Sustainable Development Goals. Geneva, SW: World Health Organization. Disponível em: http://www.who.int/gho/publications/ world_health_statistics/2016/en. Acesso em: 03 de dez 2018. 